\title{
Understanding Family Collaboration Around Lightweight Modification of Everyday Objects in the Home
}

\author{
KRISTIN WILLIAMS, RAJITHA PULIVARTHY, and SCOTT E. HUDSON, Human Computer \\ Interaction Institute, Carnegie Mellon University, USA \\ JESSICA HAMMER, Human Computer Interaction Institute, Carnegie Mellon University, USA and Enter- \\ tainment Technology Center, Carnegie Mellon University, USA

\begin{abstract}
The internet-of-things (IoT) carries substantial costs by urging households to replace their possessions with new, internet connected versions of everyday objects. Beyond financial, these costs include waste, work to arrange and orchestrate objects to suit households, and that of acquiring new skills. Upcycling domestic objects could offer households greater discretion and control over these costs by supporting the ability to tailor IoT to the home. To understand how households might do this, we conducted a home study with 10 diverse American households over 7 days to surface the approaches families are likely to use when tailoring IoT to their existing possessions. We asked family members to enact their process using endowed sticker props-IoT Stickers-to modify objects in their home. We develop a framework of how families make light weight modifications of domestic possessions, summarize trends of their object modifications, and describe the burdens such a system could impose.
\end{abstract}

CCS Concepts: • Human-centered computing $\rightarrow$ Empirical studies in interaction design; Ubiquitous computing; $\mathrm{HCI}$ theory, concepts and models.

Additional Key Words and Phrases: Smart home; social objects; family collaboration; Do-It-Yourself; sustainability; IoT; internet-of-things; End-User Programming.

\section{ACM Reference Format:}

Kristin Williams, Rajitha Pulivarthy, Scott E. Hudson, and Jessica Hammer. 2019. Understanding Family Collaboration Around Lightweight Modification of Everyday Objects in the Home. Proc. ACM Hum.-Comput. Interact. 3, CSCW, Article 185 (November 2019), 24 pages. https://doi.org/10.1145/3359287

\section{INTRODUCTION}

The internet-of-things (IoT) draws upon a long held view of ubiquitous computing: to extend computing's reach to everyday physical objects by embedding computational services in them. Generally, today's IoT envisions the adoption of these cutting-edge technologies will occur as homes replace their possessions with these new, internet connected objects. Current, commercially available IoT devices support families in upgrading their homes by switching to internet connected versions of common household objects like light bulbs [7], audio speakers [4], and blinds [6]. Even

Authors' addresses: Kristin Williams, krismawil@cs.cmu.edu; Rajitha Pulivarthy, rpulivar@cs.cmu.edu; Scott E. Hudson, scott.hudson@cs.cmu.edu, Human Computer Interaction Institute, Carnegie Mellon University, 5000 Forbes Ave. Pittsburgh, Pennsylvania, USA, 15213; Jessica Hammer, hammerj@andrew.cmu.edu, Human Computer Interaction Institute, Carnegie Mellon University, 5000 Forbes Ave. Pittsburgh, Pennsylvania, USA, 15213 , Entertainment Technology Center, Carnegie Mellon University, 700 Technology Dr. Pittsburgh, Pennsylvania, USA, 15219.

Permission to make digital or hard copies of all or part of this work for personal or classroom use is granted without fee provided that copies are not made or distributed for profit or commercial advantage and that copies bear this notice and the full citation on the first page. Copyrights for components of this work owned by others than ACM must be honored. Abstracting with credit is permitted. To copy otherwise, or republish, to post on servers or to redistribute to lists, requires prior specific permission and/or a fee. Request permissions from permissions@acm.org.

(C) 2019 Association for Computing Machinery.

2573-0142/2019/11-ART185 \$15.00

https://doi.org/10.1145/3359287

Proc. ACM Hum.-Comput. Interact., Vol. 3, No. CSCW, Article 185. Publication date: November 2019. 
non-durable goods such as paper towels can be part of the newly connected smart home through automated purchasing at the click of a brand-specific, physical button routed to online retailers [3].

This vision overlooks the costs of replacement beyond financial investment (although financial costs can be substantial [13]). Replacement contributes to waste, and if electronic, can be especially damaging [43, 57]. Discarding possessions to make room for new ones means owners must let go of their attachments to these objects and eliminate the entrenched routines and practices sustained by them $[8,54]$. New objects mean users need to acquire new skills [22], and so, renders their existing skills obsolete. Thus, adopting IoT by replacing current possessions carries many hidden costs for the home.

In contrast, upcycling can extend computing to everyday objects by adapting computing capabilities to existing possessions. Domestic possessions need not be replaced with internet-enabled equivalents. Instead, upcycling can support their renewal by retrofitting them with the latest computing capabilities. Within this vision, upgrading to a smart home consists of augmenting domestic possessions with an internet connection and related IoT services. Domestic possessions could then persist with an adaptable user interface capable of accommodating their existing forms. By being grounded in the home's already existing networks of relationships, values, and routines, these upcycled objects could offer families greater discretion and control over upgrade costs.

We sought to understand how families might make lightweight modification of everyday objects in the home with computing capabilities by conducting a 7 day study with 10 families. Using participatory design, we asked households to enact the process of modifying their home objects by attaching stickers to their possessions and endowing those objects with computing capabilities. We found there are three principal facets to the household's process to modifying domestic possessions: generating ideas, contesting and reconciling a shared model of home, and planning and programming the home. From our findings, we also summarize trends in household modification of everyday objects and present our results on household ratings of the costs for a prospective IoT Sticker system from a User Burden survey. We contribute a conceptual framework for supporting families with retrofitting computing capabilities to household possessions, and a characterization of the specific costs and modification patterns valued by families.

\section{RELATED WORK}

\subsection{Costs of Seamlessness}

The Internet of Things (IoT) vision inherits the ubiquitous computing agenda to extend computing beyond the desktop to the physical world. This agenda embeds computing in objects that have rich affordances to enable tangible manipulation of computing properties [39, 74]. The Tangible Interaction Framework built on these initial directions by situating tangible computing within a social user experience [35]. Individuation subsequently extended this framework and called attention to the routines, habits, and arrangements households use to shape a computationally enhanced object to represent or reflect relationships between household members to develop a research agenda on the social internet of things $[8,53]$. Thus, IoT became positioned as an artifact based network that facilitated embodied manipulation of computing properties and construction of one's identity and relationships.

At the same time, researchers criticized the goal of making computing disappear into everyday objects. This seamlessness goal praises computers that weave their way into the everyday environment and disappear [74]. In critique, Engaged Computing and Seamful Design emerged to argue that disappearance raises social and ethical issues [38,61]. For example, the invisible actions ubiquitous computing takes on behalf of the user lead to deskilling and obscure important decision making features of day to day planning and action [26, 61]. In trying to be unobtrusive, 
seamlessness undermines the process of investing value in an object because there is no need to learn, adapt, and personalize it [8]. Further, invisible actions can have environmental costs by encouraging digital waste through use of energy and cloud infrastructure that a person doesn't actually need or want [58]. Routines are needed to sustain artifacts over time and help realize values of durability and sustainability [8]. IoT risks creating substantially new environmental and social costs if it ignores the routines and relationships computationally enhanced artifacts will be a part of.

\subsection{Redesigning for these Costs}

For the past decade, researchers have begun to worry about computing's costs. Through its preference for newness, the modern American household's excessive material consumption can have negative side-effects. These include increasing stress, deteriorating health, growing landfills, short life-cycles for non-renewable on non-biodegradable materials, and enlarged energy demands $[9,11,51,59,68,73]$. Redesign for these costs will need to consider how artifacts can change relationships people have to them and to each other [27, 41]. Domestic objects socialize others, and in the United States, realize family ideals to nurture member growth, talents, creativity, selfexpression, and identities [2,32]. An object's life-cycle and reuse is part of symbolic activity that carries layers of nuance such as gift-giving $[1,73]$. If objects are to persist, craftspeople are essential for supporting their reuse [73]. Alternately, an object may be discarded or destroyed to sever the relationship it is a part of [1]. The values and relationships objects help realize will need considered when addressing the costs of computing consumption.

As a technology that has not quite arrived, studies of the values and relationships around IoT are limited. Researchers have criticized IoT for neglecting questions about how objects augmented with communication and data sensing capabilities will be used in domestic settings [8]. In an analysis of three case studies, researchers argue that IoT can support the owner's identity, agency, and autonomy by giving control to owners over their participation, sharing, and arrangement of the device within the home [8]. Do-It-Yourself IoT (DIY-IoT) is a class of IoT devices that may offer end users greater discretion and control over this process $[14,18]$. However, to date, DIY-IoT needs to be designed to support 1) reflecting on routines to identify appropriate IoT interventions, 2) debugging, 3) facilitating family feedback on IoT intervention, 4) interpreting a device's state, and 5) installation [14]. How these DIY-IoT processes interact with other activities and values in the home will need to be surfaced to make progress on this agenda.

While IoT technologies, as such, may have overlooked domestic values and relationships, significant progress has been made in this area for systems focused on energy consumption, eco-feedback, and persuading home dwellers to be more environmentally friendly. For example, prior work developed a set of three personas-the helper, the optimiser, and the hedonist-to characterize the impact of identity on energy saving [40]. The desire for energy savings that can be central for upgrading to a smart home, can still conflict with other aspects of a person's identity and become entangled in household dynamics of compromising with other householder's desires [40]. Some household members lack agency and discretion to control smart home infrastructure. Socioeconomic class may in part determine whether residents are able to monitor their energy usage or fix a building's inefficiencies [23]. Further, since many household resources are shared, household members do not have the discretion to make unilateral decisions [21]. Rather, setting a device's state and controlling its usage is an interdependent decision [21]. Researchers have created display technologies to equip these uses with more information on what data has been collected, what the household's resource usage is like, and to further reasoning over what has happened in the home [18, 28]. One concern is that the way the household's resource usage is made visible to the user is underpinned (whether implicitly or explicitly) by specific models of behavior change and persuasion [28]. In contrast, 
end user programming (EUP) could enable users to investigate and reflect on their home's data or explore their own questions without imbuing the interface with particular persuasive techniques [18]. While revealing raw data streams might avoid assumptions of a one-size-fits-all model for the home, even an approach which reveals minimally curated data will still confront household politics and require research effort to determine what design requirements best accommodate household members' conflicting interests $[18,20,38,76]$.

\subsection{IoT Tailoring and Agency}

There are challenges to fostering a culture of customization for IoT. End-users are unlikely to adopt smart home devices as a wholesale upgrade to their home [25]. Instead, these devices will enter the household in piecemeal fashion as small improvements or reappropriations [14, 22, 25, 56]. This will lead to a highly complex network of home technology that will be unlikely to conform to any single manufacturer domain/platform or even technical standard [22,25]. Studies of this process have found that specific household members specialize in learning and programming IoT devices $[14,50,76]$. This verifies earlier findings that households have difficulty sharing access and control of devices among family members $[22,60]$. Specialization often belies skill gaps and objects becoming gender stereotyped $[22,60,76]$. When one household member programs a device and another must live with it, family members' emotional reactions to those programs can have large implications for acceptance [14, 20]. Early work on software tailoring culture developed a rough model of these disparities: greater customization will require greater programming skills [48]. However, a community can foster a climate in which more expert members assist lower skilled members with learning the things they need to gain greater control of software systems [29, 48]. Design will need to facilitate community relationships that foster tailoring in DIY-IoT to counteract structural forces that push families to concentrate access to home networks in one member.

Despite past work to foster tailoring communities, barriers to novice uptake of tailoring remains. Many systems have tried to lower the challenges to novices in system design. A prototype language enabled more skilled users to write code for the actions of on-screen buttons and novices to copy and reuse those buttons without needing to know anything about the underlying infrastructure [48]. Other systems created metaphors-such as jigsaw puzzle pieces or magnetic poetry-for novices that abstract away from the system's details, but can be combined and arranged to compose small programs [36, 71]. In today's IoT systems, if-then rules in the form of trigger-action recipes are commercially available and widely used [5]. They show promise for lowering the barrier to skill transfer between expert and novice users [31, 72]. Yet, novices continue to wrestle with aligning their IoT ideas with the if-then structures of trigger-action programming and in one study, selection of triggers and actions had the lowest usability ratings of all measured dimensions [31]. Participants struggled with making an appropriate choice among available components such as choosing between event triggers or condition triggers [31]. These studies show how control constructs, component design, and appropriate metaphors can lower barriers in tailoring systems for novices. We contribute to this body of work by investigating how an IoT that supports tailoring could better support alignment between DIY-IoT ideas and IoT services.

\section{IOT STICKERS}

Upcycling proposes an alternative vision for IoT: use the household's everyday possessions to enable household members to make 'dumb' objects 'smart' by attaching a wireless, battery free sticker to the object. Recent developments in RFID interaction techniques, back-scatter signal detection, and athome fabrication make this vision possible through IoT Stickers [10, 30, 34, 42, 45, 47, 66, 75]. These technologies are approachable to the typical household through RFID-based sticker technologies 
with widget-like interaction techniques such as clicking a button or sliding a scroll bar $[47,66]$, along with lightbulb form factors for RFID readers [34].

Our work extends this prior research in two ways. First, we provide a systematic investigation of how households might tailor IoT stickers to the domestic environment using an experience prototyping method with sticker props [64]. Following prior work [37, 48], we used the IoT Sticker button-like interaction technique to explain to participants how a tailorable IoT system might work and to enable them to enact their design ideas in a domestic setting. Second, we provide a framework for supporting family members in upcycling their possessions. Unlike prior work, we develop a conceptual framework that bridges the work households already do to incorporate objects into their routines and home with the specialized knowledge needed to augment objects and integrate them successfully.

\section{METHODS}

We conducted a 7 day, in home study to uncover household approaches to using IoT Stickers to retrofit their possessions with IoT services. To do this, we asked households to consider which objects to augment with IoT capabilities and enact this process using endowed sticker props. We describe our approach below.

\subsection{Participants}

We recruited 10 households for our study from a mid-size American city. We sampled participants across gender, age, race, class, disability, and household structure in line with persistent categories of concern to the HCI research community $[24,63,76]$. We also chose these in part because our participant pool's demographic distribution could be approximated from public records [33, 49]. We excluded potential participants if, (1) working with them would require changing our protocol (e.g., translator or adapting materials for intellectual disability), (2) their household had changed over the past year (e.g. baby, divorce, or new roommate), (3) they lived alone, or (4) required by our screening tool (see below). Our criteria slightly shift our population away from a representative sample for our recruitment city. For example, our 2.9 average persons per household and entire population lived in the same home one year ago is greater than the city's averages of 2.1 per household and $77.8 \%$ in the same home [17]. We include children $<5$ yrs. and those with severe intellectual disabilities by proxy in participant interviews, but we did not directly work with these family members.

We recruited through several NGOs and public organizations using word of mouth or flyers. We screened participants using a 5 minute questionnaire that probed household structure, income, home ownership, languages spoken, work status, and disability. To ensure we had a representative sample, we used this questionnaire to exclude potential participants if we had a sufficient number of households with similar answers. We required all household members participate and commit to the entire duration of the study.

\subsection{Procedure}

The study took place in participants' homes and lasted 7 days. This consisted in a 1.5-2 hour home visit the first day, a diary study the next 5 days, and a final 1-1.5 hour home visit the last day. We accommodated scheduling needs by relaxing the study timeline to end between the 7 th and 10th days. One household's child did not participate the last day despite our study requirements. We consented participants according to Institutional Review Board (IRB) protocols, and included assent from children 5-18 years old with parental approval. We paid each adult participant $\$ 15 / \mathrm{hr}$ and each child $>5$ years, $\$ 5 / \mathrm{hr}$. 
4.2.1 Home Tour and Sticker Task. On the first day, we conducted two tours of the home with different mixes of family members. For families with children, this meant that each parent led one tour while the children participated in both tours. For one family made up of three roommates, this meant two roommates at a time led each tour, with a third roommate swapping out for different portions of the tour. This allowed us to interview each adult in isolation, remain within our allotted study time, and collect shared perspectives of the remaining family members concerning household objects. During the tours, we asked family members to show us five rooms. In each room, we asked them to select three objects that they would want to modify with computing abilities and three objects that they would want to keep in the same condition without augmentation. We then asked them to describe their augmentation and reason for selecting the object. This helped us encourage envisioning the upcycle process, and allowed us to collect data on objects inappropriate for IoT.

At the end of the first visit, we instructed participants on how to enact a sticker modification and complete the audio diary portion of the study following an experience prototyping method. We first asked participants to select an object, describe the new abilities they would give to that object, and to provide a detailed characterization of how the new capability would work or change the environment. We left an audio-recording USB stick with each family, reminder instructions, and a pack of Avery office stickers to use as props. We facilitated a practice entry with participants before leaving. We reminded participants to make a diary entry each day by texting them for each of the subsequent five days. During the last session, we asked participants to demonstrate to us their process of making an entry. Next, we asked participants to show us their diary objects and to describe their modification to us in case of device malfunctions and to capture shared household assumptions undescribed in the audio diaries.

4.2.2 Semi-structured Interview. We then interviewed the family about how the sticker task went using a semi-structured protocol [46]. Questions included asking how the process went, how participants generated ideas for their objects, and how much time it took.

4.2.3 User Burden Scale. Following the interview, we asked each participant to fill out a user burden questionnaire. The questionnaire adapted the difficulty of use, privacy, and financial dimensions from the User Burden Scale to suit questions for an IoT sticker system [67]. We framed privacy questions in terms of current policies on commercial IoT devices. To measure user sensitivity to device cost, we valued IoT stickers at $\$ 0.10$ and IoT lightbulbs (required as a reader for IoT Stickers) at $\$ 300$ from previous research [34].

\subsection{Analysis}

We video-recorded all in home sessions and had the audio data from the diaries and home studies transcribed by a third party transcription service. Because of device malfunction, we do not have audio diary data for P5. For the home tour data, we coded for objects participants modified, those they kept unmodified, and their reasons for doing so. With the results, we created a dataset of objects that included who tagged the object, what room it was in, its modification code if any, and a reason code. We provide descriptive statistics for general trends in this dataset. We then analyzed the other transcripts using thematic analysis to characterize families' process of tailoring an IoT Sticker system to their home. For the user burden questionnaire, we summarized our findings with descriptive statistics.

We exclude P1 from most of our analysis because the last session and the audio diary data revealed that the household did not use the sticker props to enact the upcycling process. We do include P1 in our object modification dataset and the user burden survey results. We discuss this exclusion further in the discussion. 


\begin{tabular}{|c|c|c|c|}
\hline \multicolumn{4}{|c|}{ Indicators of Class } \\
\hline Income Ranges ${ }^{a}$ & Midwest, Amer. City & Study Pop. & Households \\
\hline$<\$ 10,000$ & $12.4 \%$ & $0 \%$ & 0 \\
\hline$\$ 10-14,999$ & $7.5 \%$ & $0 \%$ & 0 \\
\hline$\$ 15-24,999$ & $12.5 \%$ & $10 \%$ & 1 \\
\hline$\$ 25-49,999$ & $23.9 \%$ & $10 \%$ & 1 \\
\hline$\$ 50-74,999$ & $16.5 \%$ & $50 \%$ & 5 \\
\hline$\$ 75-99,999$ & $9.8 \%$ & $10 \%$ & 1 \\
\hline$\$ 100-149,999$ & $9.8 \%$ & $10 \%$ & 1 \\
\hline$\$ 150-200,000$ & $3.6 \%$ & $0 \%$ & 0 \\
\hline$>\$ 200,000$ & $4.3 \%$ & $10 \%$ & 1 \\
\hline Education Level $^{b}$ & Midwest, Amer. City & Study Pop. & Participants \\
\hline$<$ High School & $8.1 \%$ & $0 \%$ & 0 \\
\hline High School & $27.6 \%$ & $5 \%$ & 1 \\
\hline Associates & $7.9 \%$ & $15 \%$ & 3 \\
\hline College & $21.3 \%$ & $30 \%$ & 6 \\
\hline Graduate & $19.4 \%$ & $35 \%$ & 7 \\
\hline
\end{tabular}

${ }^{a}$ For our 8 married households, the comparison for married couples may be more appropriate: $26.6 \%<\$ 50 \mathrm{k} ; 19.2 \%$ $\$ 50-<75 \mathrm{k} ; 15.4 \% \$ 75-<100 \mathrm{k} ; 19.9 \% \$ 100-<150 \mathrm{k} ; 8.5 \% \$ 150-200 \mathrm{k}$; $10.3 \%>\$ 200 \mathrm{k}$

${ }^{b}$ Based on adults $>25$ years old; For the household of adults $<25$, comparisons with adults 18-24 years would be appropriate: $22.3 \%$ bachelor's or higher (in our study, $100 \%$ of this 1 household).

Table 1. The chart shows the representation of different classes in the local population relative to the households represented in the study's population. We used income and education to characterize the class structure of our population in line with standard conventions using income, education, and job type.

\section{FINDINGS - COMPOSING AN OBJECT MODIFICATION}

Overall, families grappled with three principal facets-idea generation, the model of home, and planning/programming home-of tailoring an IoT Sticker to an object. To generate ideas, participants needed to distance themselves from their environment to consider how they might modify their possessions. We characterize this distancing, how objects seeded ideas, and the environment's function as a source of ideas in the section Idea Generation. In this section, we also describe trends in participants' initial ideas to tailor IoT to their possessions. Next, we found that object modifications potentially destabilize the family's shared model of home, and they can serve to stretch the family to consider new arrangements never before considered. We summarize this in the second section. Finally, families do substantial work-including coordinating and collaborating on proposals- to get buy in, implement their ideas, and foster trust in how the home will change. We characterize this process in the section Planning and Programming Home. We describe participant demographics, present our findings, and share our resulting framework in more detail below.

\section{Participant Demographics}

We recruited 10 families composed of 29 household members and 26 participants $(42.9 \%$ identified male and $57.1 \%$ female). We had slightly more females than our city (51\%) [17]. Participants ranged between 9 to 70 years of age ( $M=35.8$ yrs., $S D=20.2$ yrs.; City $M D=32.9$ yrs., [15]). Our study's 


\begin{tabular}{|c|c|c|c|c|c|c|c|c|c|}
\hline \multicolumn{10}{|c|}{ Race \& Ethnicity } \\
\hline & & English & & Amer. & & Black/ & Hawaiian/ & & \\
\hline & Citizen & $\begin{array}{l}\text { 2nd } \\
\text { Language }\end{array}$ & Hispanic & $\begin{array}{l}\text { Indian/ } \\
\text { Alaskan }\end{array}$ & Asian & $\begin{array}{l}\text { African } \\
\text { American }\end{array}$ & $\begin{array}{l}\text { Pacific } \\
\text { Islander }\end{array}$ & White & $\begin{array}{l}\text { Two/More } \\
\text { Races }\end{array}$ \\
\hline City Pop. & $91.5 \%$ & $10.8 \%$ & $2.8 \%$ & $0.2 \%$ & $5.5 \%$ & $24.3 \%$ & $0.0 \%$ & $66.3 \%$ & $3.2 \%$ \\
\hline Study Pop. & $75.9 \%$ & $24.1 \%$ & $13.8 \%$ & $3.4 \%$ & $10.3 \%$ & $27.6 \%$ & $0.0 \%$ & $37.9 \%$ & $6.9 \%$ \\
\hline Households & 8 & 2 & 1 & 1 & 1 & 3 & 0 & 5 & 2 \\
\hline \multicolumn{10}{|c|}{ Household Structure } \\
\hline & $\begin{array}{l}\text { Female } \\
\text { Headed }\end{array}$ & $\begin{array}{l}\text { Male } \\
\text { Headed }\end{array}$ & $\begin{array}{l}\text { Married } \\
\text { Opp. Sex }\end{array}$ & $\begin{array}{l}\text { Same Sex } \\
\text { Couples }^{1}\end{array}$ & Children & $\begin{array}{l}\text { Neither } \\
\text { Par. Em- } \\
\text { ployed }^{2}\end{array}$ & $\begin{array}{l}\text { Mother not } \\
\text { Employed }\end{array}$ & $\begin{array}{l}\text { Father not } \\
\text { Employed }\end{array}$ & $\begin{array}{l}\text { Both Par. } \\
\text { Employed }\end{array}$ \\
\hline City Pop. & $29 \%$ & $8 \%$ & $63 \%$ & $1.4 \%$ & $44.1 \%$ & $3.8 \%$ & $26.3 \%$ & $7 \%$ & $62.9 \%$ \\
\hline Study Pop. & $20 \%$ & $0 \%$ & $70 \%$ & $10 \%$ & $40 \%$ & $25 \%$ & $25 \%$ & $0 \%$ & $50 \%$ \\
\hline Households & 2 & 0 & 7 & 1 & 4 & 1 & 1 & 0 & 2 \\
\hline
\end{tabular}

${ }^{1}$ Same sex couples city comparison figures are for the entire US.

${ }^{2}$ Employment city comparison figures are for the entire US.

Table 2. The chart shows the representation of different racial and ethnic groups, household structures, and working parents in the local population relative to the households represented in the study's population. The number of households present in our study for that subpopulation is given below the percentage.

age distribution approximated the city's population trend with $8.7 \%<5$ yrs., $34.8 \%<18$ yrs., $65.2 \%$ adults $<65$ yrs., and $21.7 \%$ adults $>65$ yrs (City: $5 \%<5$ yrs., $15.8 \%<18$ yrs., $70.2 \%$ adults $<65$ yrs., and $14 \%$ adults $>65 \mathrm{yrs}$ ) [17]. Seven participants reported a disability. This prevalence in our study is, at times, higher than the city's: $9.1 \%<65$ yrs. (compared to $9.9 \%$ for the city) and $83.3 \%>65 \mathrm{yrs}$ (compared to $13.6 \%$ for the city) $[15,17]$. We further summarize our participant pool in Tables 1 and 2 (sources $[15-17,55]$ ).

\subsection{Idea Generation}

Modifying an object with IoT begins with coming up with an idea. At times, the object itself is the source of inspiration. However, households also used other sources such as caring for a family member or wishing to completely change a room. When generating an idea, families decide which objects are appropriate interfaces for IoT.

5.1.1 Choosing Objects for Upcycling. Our dataset revealed 17 different rooms and 267 objects as candidates for IoT interfaces. Participants designated a total of 219 objects to leave unmodified with IoT. The largest number of objects to modify were in the bedroom (53), bathroom (52), living room (42), kitchen (35), and office (18). These 5 rooms contained $74.9 \%$ of all modified objects and $77.2 \%$ of all unmodified objects (see Figure 1 for a breakdown of objects for each room). Nine rooms were chosen by only one or two households: guest room, baby's room, dining room, door/doorway, hallway, outdoors/porch, sewing room, TV room, and storage. These rooms fell into three categories: liminal spaces, such as hallways and doorways; dedicated activity spaces, such as rooms for sewing or watching TV; and spaces for other people, such as a baby or guest.

Bedroom. The bedroom contained the most selected objects in the study (modified: 53; unmodified: 52). Many cherished objects, such as gifts, resided in the bedroom. Participants thought these obvious targets to keep unmodified by IoT. Participants were attached to many objects that connoted comfort and relaxation. For example, the bed was the top item to keep unmodified in the whole study (9 participants). P1b explained, "It's very comfortable...I have seen those beds that rise up with a remote...but I think my bed is great how it is." Participants described their furniture as aesthetically appealing and fitting well (4 unmodified). The bedroom TV had the most divided opinions (5 modified, 4 not). Participants modified the TV with upgrades to fit fashion: networking, 
Object Modifications by Room

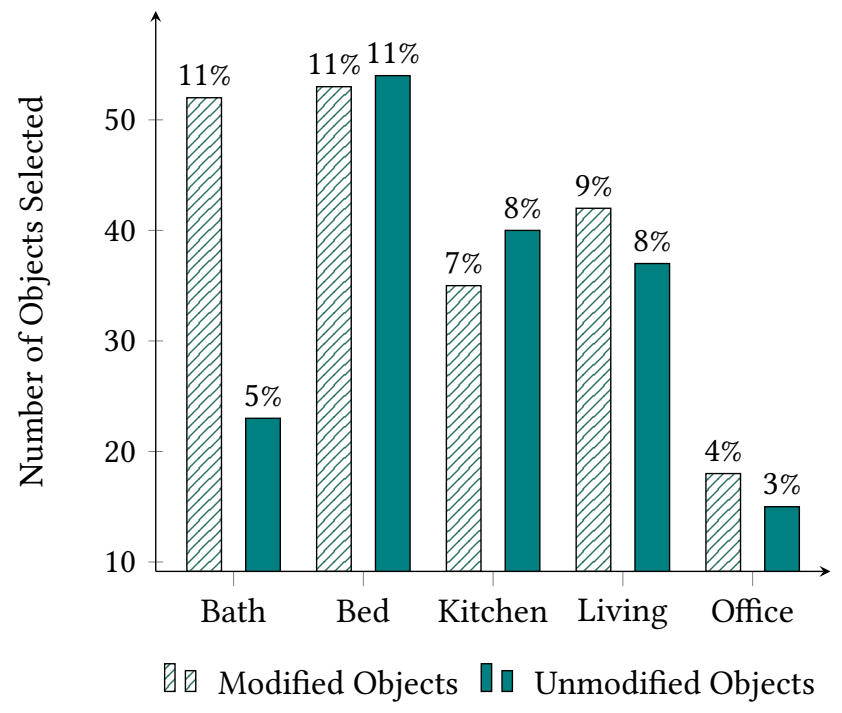

Fig. 1. The bar graph shows the distribution of objects across the five rooms with the most number of selected objects from participants. Each room shows the comparative number of objects participants wished to modify with IoT capabilities to those they wished to remain as they are, apart from an loT network. Percentages above each bar show the percentage of the total object inventory from the study found in each room.

mounting on the wall, or to simply have one in their room. Others thought their current TVs worked well, didn't think modification worth the cost, or weren't appropriate for a child's room (P5b). They modified lights to be turned off from the bed (6 participants) and the closet to manage items and recommend fashion choices (4 participants). The bedroom contained the most number of cherished items that were inappropriate IoT interfaces, but also contained many objects which could change the environment to be more comfortable and helpful.

Bathroom. The bathroom was the only room with an unbalanced number of modifications: over twice the number of modified items to unmodified ( $52 \mathrm{v} .23$ unmodified objects). In contrast to the bedroom, participants were little attached to bathroom objects and there were few they wouldn't modify. P4b dismissed bathroom objects, "No, there's nothing we want to keep-no, we'd change the whole thing, change it all out." Most often, objects were to be added (9 participants) or replaced (4). They targeted the shower, toilets, and tub for renovation. The top reasons to modify an object were to increase comfort of the room (6 participants) and to improve mood (8). Two of the top 3 objects to remain unmodified were part of plumbing: the sink already worked well (5) and some had an aversion to any kind of modification to the toilet (2). In general, participants wished to not simply augment existing objects, but completely renovate their bathroom.

Kitchen and Living Room. The kitchen and living room's objects led to divided opinions across family members on how to modify shared objects. Family members disagreed over modifying the refrigerator (manage the food inventory or attach screens; 7 participants) or whether it already functioned fine (unmodified by 6 participants). In 4 of the 8 households, family members in the same home disagreed. Similarly, some family members found the stove frustrating to use (3 modified) and others thought it worked well (5). Notably, two children did not want the stove to be modified because they were just learning to use it and that was difficult enough (P5c and P5d). In the living 
room, the television inspired indecision (5 undecided). They wanted to modify it to fit with fashion (8; see bedroom TV discussion), but were also satisfied with how it functioned (7). Unlike the bedroom, living room furniture was not always kept unmodified (5). Changes included adding missing items (3) and making them more accessible or easier to use (2). However, many participants were attached to their existing furniture (9) and features of the room itself-floating shelves, chimney brick, or the room layout-because they thought they were aesthetically pleasing. Like the bed, the couch was considered an object of comfort that shouldn't be modified (4 participants). In the living room, almost half of the objects selected as inappropriate for IoT were so because they were aesthetically appealing (16 of 37). Family members disagreed the most over modifying shared objects in both the living room and kitchen.

5.1.2 Finding Ideas. Families generated ideas for modifying an object using methods such as brainstorming, problem solving, and defamiliarization. Problem solving has been covered elsewhere $[14,50]$, so we focus only on brainstorming and defamiliarization here.

Brainstorming. Family members took turns describing their ideas to the rest of the family. P9 rotated ideas by day, "We each had ideas. Oh, that's a good one, so we'll do mine today, and we'll do that one for tomorrow" (P9a). During this time, family members listened to each others' ideas, generated extensions, tried to envision them, and clarify what others had in mind. P10's ideas evolved from one anothers',

P10b: We would collect...on some days and decide on an object-and we'd spend half an hour brainstorming as to which object we were going to select for that particular day, and how's it going to work, and once we had a rough structure ready, then-P10a: We started answering the questions, and more often than not we came up with totally different systems-P10c: With new ideas, and then we started recording.

Brainstorming was a time to ask questions and empathize with other's envisioned changes. Although we instructed participants to record their entire process, brainstorming usually happened offline. P3a wanted her family to be perceived as competent; "This was our process-talking about it before we sound stupid." We learned about brainstorming during our last day session when we asked participants to walk us through their sticker modification process.

Defamiliarization - To generate ideas, family members began questioning their household. Defamiliarization enabled members to reflect upon their familiar environment and reconsider domestic possessions anew. To do this, "[P9a] just walked through every room looking at everything." Participants would cast about the room looking for objects to modify, walk from room to room searching for material inspiration, and at times, reconsider their ingrained routines. Three participants went through each room in turn. The room strategy helped with systematically exhausting room based sources of inspiration: "We did the mailbox, the pantry, the bathroom. We haven't done anything in the basement. Is there anything we could do in the basement?" (P2b) Occasionally, walking itself would stimulate reflection on a behavior or object. P4a "walked out of the room. Came back. [P4a] said, 'Oh. I left the light on.' And by the time [he was] going in and out of the room and coming downstairs", he had generated an idea for modifying the light. As several days passed, participants began to view their objects differently while going through typical activities. One day during the study, P9a was reading a book on the porch. She then realized that she frequently dozes off, and she decided to add a sticker to her lounge chair to set an alarm to wake her up after an hour. Participants were able to generate ideas through distancing themselves from their environment.

Defamiliarization pushed family members to reflect deeply on their lives. P4a explained that, "It sort of let [him] reflect to see what was actually going on in [his] home". Two family owned homes struggled with modifying their household objects because of the years of invested effort tailoring it to their needs. P9 "had the house setup pretty well as it is. It's pretty organized, functional in its 
layout...[They] were just thoughtful over the years." The time of owning and living in their own home benefited the household's arrangement. In contrast, defamiliarization diminished P2's-an immigrant family living in a rented townhouse-view of home. "Then you start to see your house as very archaic, you know? You're like, oh, this is bad. I don't like that" (P2b). Defamiliarization helped families reflect upon their values for home, but could also surface problems that were not always something a person wished to focus on.

5.1.3 Summary. Families generated ideas for tailoring IoT interfaces to their home by using objects and rooms as sources of inspiration during brainstorming or defamiliarization. Intimate spaces like the bedroom and bathroom were targeted as sites for modification with IoT, but felt that objects connoting comfort and aesthetics should remain unmodified. Objects in shared environments, like the kitchen or the livingroom, generated disagreement over whether the object should be modified at all and what form modification should take. Yet, families found ways to work through modifications. Brainstorming was a collaborative process for empathizing with others and evolving new ideas, while defamiliarization was a solitary process that pushed families to reflect on how their values were realized in their home. The process of idea generation called for suspending belief in the current home to consider reconfiguration.

\subsection{Contesting and Reconciling the Model of Home}

During idea generation, families articulated a model of home that shaped how members interacted. In doing so, participants delimited the roles expected of one another, society's imposed constraints, and their views on what might be both technically and socially possible. Modification ideas could serve to destabilize the model of a functioning home. Specifically, object modifications mediated these boundaries by constraining the discussion or offering an alternative domain through metaphor.

5.2.1 The Family's Idea of Home. To explain their ideas, family members articulated a well functioning verses a dysfunctioning home. They designed object modifications to get rid of dysfunction. If P6b modified the oven, "then the house won't smell like fried chicken", or P4b's modification "would eliminate [the blinds] being broken or crooked and having to continuously replace them." Modified objects would make the home function better. When P5b excitedly told her family, "there's a button next to [the toilet] that you can just press and it'll sanitize it for the next person". With this change, P5b described her better functioning home where she didn't clean the toilet. Object proposals supported family members in changing the shared idea of the home and its arrangements.

Equipped with an object idea, a family member would then build consensus or buy in from others for the proposed modification. Even if the household generally went along with one person's ideas, family members would check in with others to see whether they would use the newly modified object. Would they benefit? P10a asked, "What if we had this in the fridge? If we had this feature then what would we use it for?" Check-in also tested whether others would use the object in the envisioned way, or appropriate it. P5b explained, "He and I discussed completely different ideas for each thing, too. We had completely different-I like this and this, and he had different reasons." By reaching consensus, family members created the boundaries and implicit constraints of the household.

Some objects challenged the shared model of home and shaped change. Usually, these modifications directly targeted household roles and not the objects themselves. For example, both P2b and P6b-stay at home moms-wanted to modify objects in the house that they didn't want to be responsible for any longer. P6b confessed that living with 4 males (2 young boys, and 1 boy potty training) meant she cleaned the toilet daily, and she found it disgusting. She modified the toilet to clean itself. P2b frankly told her family that they should modify the fridge: "To waste less, and to think less, because I find it very, very tiring to think about what I am supposed to do for you." These 
modifications revealed to other family members that the household member thought it problematic that they were expected to care for some objects in the home.

5.2.2 External Models and the Home. Societal norms constrained object modifications. These norms set expectations for the home and members' roles. In turn, these norms informed the features of modified objects. Participants used norms to justify properties like pay per use:

There would also be built in [the oven a] command system for paying when you're ordering like that, so that they can get your money. They're not just going to send it on our word. (P6b)

Other norms included parents cooking healthy meals for children (P2b), or apartment residents being responsible for purchasing their own equipment to guard against power surges (P7b). Family members used norm accommodating features to free up their own time and attention. For example, P2b's imagined refrigerator provided guidance to her children on how to create their own lunches with the food available. P2b was happy to be relieved of teaching her children how to do this. Guidance could come from other sources as long as the children had enough help to proceed independently. Using norm modifications, family members offloaded societal expectations to the household's objects. This meant family members would no longer be personally required to intervene, but they could be assured the norms were upheld.

External models aided family members with proposing a household reconfiguration. Participants pulled ideas from hotels, restaurants, grocery stores, and public restrooms to import these external functions into the home. These places functioned as reconciling metaphors that illustrated proposed changes to others. For example, P2a worked to clarify P2b's idea asking, "It's like Walmart, right? In the house." Public places illustrated how similar kinds of objects existed elsewhere, but organized social relationships differently. These external models filled gaps in explaining how the object modification would work and what changes it would entail. We further discuss interaction between external models and other facets-like brainstorming-in the Framework section below.

5.2.3 Determining What is Possible. Family members diverged in how much they constrained their object modifications by what they thought was technically feasible. Three family members became worried about whether the ideas could be implemented, and notably, they also had a career in a technical field (a systems administrator (P5a), a database administrator (P8a), or a systems analyst (P2a)). They worried some ideas stretched the limits of possibility, and could present obstacles to object ideas. P2b thought his family members "All sort of know what the problems are and what we would like to have, but we didn't know if it was possible" (p2b). Coming to a shared sense of what would be a feasible modification was difficult for many household members, and caused them to remark that they might be just engaging in "wishful thinking" (P8a), or struggling with "first world problems" (P9a).

Other households and family members were content to imagine something new and grew attached to their ideas. These families gained confidence by nurturing an alternative vision of home: "We realized we're both technical geniuses" (P3a). These families enjoyed approaching their house as a design material. P5b began to consider other ways to limit screen time in children's rooms, and remarked, "I had never thought of shutting the Wifi off in certain rooms only." The process pushed families to address household issues differently. One household directly disregarded technical feasibility. P6a disagreed with his wife, "Oh I've seen enough Star Trek. If they can do this, and they can do that. Why can't [we]-you know?" When families wrestled with determining what they could possibly implement in their homes, they stretched the family's shared model to include alternative household configurations. 
5.2.4 Summary. Each family elaborated a model of how the home worked by implicating their relationships when modifying objects. Object modifications served to critique the family model by highlighting ways it could be better or is currently dysfunctional. By changing attributes of the objects that were central to the family model, family members created alternative roles and relationships for themselves. Societal expectations and norms shaped the family's model of home This external model constrained the home model, but also suggested desirable alternatives. When considering possible modifications, families destabilized the current working model and extended it to include previously unimagined alternatives.

\subsection{Planning and Programming the Home}

While a few families only had one member create object modifications, most families worked on the modifications collaboratively. Working together required time, planning, and coordination throughout the work week. The majority of time spent on modifying an object consisted of coming up with an idea. Collaboration could fuel this process, but required family members coordinate their schedules to do so. Even if family members did not directly collaborate, part of maintaining trust included clearing ideas with family members and ensuring their views were represented in the modification.

5.3.1 Taking Time to Modify the Home. Participants spent most of their time on coming up with ideas for household objects. Although we instructed participants to document their ideation process in the audio diaries, none of the households fully did this. Participants reported that coming up with ideas took anywhere from one minute to two days. Four households admitted that for the first few days, they had no problem coming up with ideas, but then they hit a creative wall. This pushed participants into taking time outside of the recorded time of creating an audio diary entry. They used this time to reflect on their own, bounce ideas off other family members throughout the day, or delegate responsibility to others. Excluding this ideation time, participants reported the sticker task took between 3-45 minutes. Our audio diary data revealed that participants took a maximum time of 10.5 minutes to create an entry, and suggests that the recording was usually prepared in advance.

5.3.2 Planning Modifications. Except for two households, families planned and coordinated their modifications collaboratively. Four households found collaborating on an idea fun by introducing new dynamics into their relationships. P3b described how the activity changed her interaction with her partner: "I would get home a little bit earlier so we could do the audio diaries before she went to sleep. We would have conversations that we never had before." Three households described coming to a creative halt where they struggle to think of new ideas.

P9a: The first three days were kind of fun...Then that fourth day we hit...P9b: It seemed like it became more of a chore, and it was hard to think creatively about what else we were going to do. It became more like homework.

These three families used a process of modifying objects that they had always wanted to change or that emerged during the first day's study interview. Once they had documented their legacy ideas, they struggled to generate new ideas. Collaborative approaches seemed to guard against this halt One family changed their groupings, "We always sort of switched...I think its a different dynamic, also." (P2b). Interleaving different pairs helped larger families generate alternative approaches and new ideas.

Coordination was important for building the rest of the household's trust in the system. Three households used spare moments throughout the day to ensure everyone's views were represented, 
even if that partner would not be home to participate in making the audio diary. Coordination led to greater certainty for family members not present.

Even when I wasn't home and not doing the diary. I knew what [P7b] was going to be doing and already kind of understood what he would be talking about. So it wasn't like [he] made this new function for our house and didn't tell [me] about it. Like, it was there. I knew what was going to happen. (P7a)

Households that used coordination over collaboration for planning largely delegated the task to one household member rather than do the task collectively.

5.3.3 Programming the Home. Once decided on an idea, the family needed to shape that it into a workable modified object. To do this, participants desired the ability to manipulate features of the object's new properties to adapt it to its context. Newer families (together $<10 y$ rs.; 4 total) directly wanted to program their modifications with a voice interface or smartphone. They described manipulating parameters such as setting a timer or creating if-then relationships that let them control household objects remotely through buttons on their phone. Older families ( 5 total) focused on complex processes that were already part of their ingrained routines such as making grocery lists, seeking out recipes, preparing dinner, cleaning the toilet, upgrading software, and adjusting the lighting at different times of day. These families tailored objects according to subtasks that were already part of their typical activities, but the modifications allowed them to offload the work to the object or distribute it across multiple people instead of one. Workable objects for newer families drew from newer user interface paradigms, but for older families drew from entrenched activities or routines.

5.3.4 Local Leads. We observed patterns of family dynamics in the audio diary data. In every household, one member assumed a central role-we call this the local lead-in creating object diary entries. We identified 3 characteristic patterns that this member assumed: specialist, manager, and leader. For households with a specialist member (2 households), they created almost all of the diary entries for that household. Theirs was the only voice in the data, and they provided the most detailed description of modifications. Our data suggests that these specialists worked in isolation to generate an idea and work through its implications. Manager households included other family members in the audio diaries, but the manager was the only person who was consistently present for most of the sticker entries (4 households). They facilitated a complete description of an object idea such as making sure the object was given a name and fully specifying how the idea would work and/or modify the household environment. Lastly, for households with a leader, object modifications were guided and directed by these people ( 2 households). Much like a specialist, object ideas tended to be that of the leaders and so they also provided the most detail and worked through the idea's implications. Yet, unlike specialists, leaders did not work in isolation, and usually all household members were present. Unlike household managers, leaders did not facilitate other members' ideas or work to translate the ideas of others into a complete description. The ideas described were usually their own, and they persuaded other members to go along with them.

5.3.5 Summary. Object modifications made demands on family members time, and families differed in how they managed these demands. Some families carved out a specific time of day to work collaboratively. Other families coordinated throughout the day and tasked one family member with implementing the idea. Newer and older families differed in the ways that they desired to realize their ideas. Newer families were aware of new interfaces and were eager to implement them in their own ideas. Older families had established family routines and hoped that the modified objects could pick up some of the work or help with coordination. As families developed patterns, local 


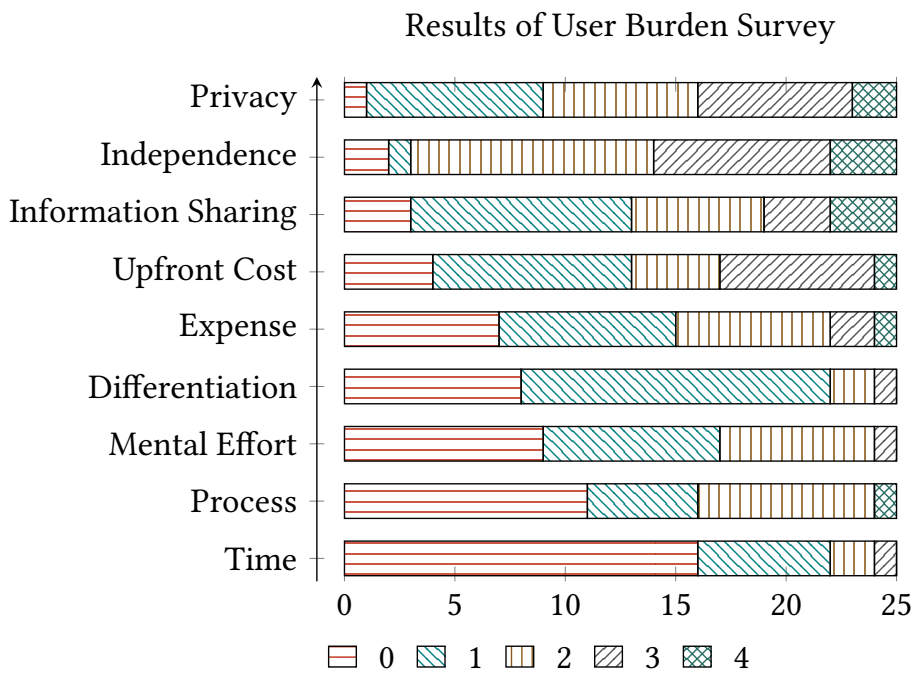

Fig. 2. The stacked bar chart shows the distribution of family members' responses to the adapted User Burden Survey. The survey consists in a 5-point semantically anchored scale ranging from 0-4. Average participant ratings on all measured dimensions were between 0.5 and 2.36 indicating a moderate to low burden for a prospective loT sticker system.

leads emerged through working on their own ideas, persuading others to adopt them, or facilitating others' ideas into working modifications.

\subsection{Costs}

In our survey of user burden, participants thought that an IoT Stickers system presented a low to moderate burden to their household. On average, most of the measured user burden dimensionsprivacy, financial costs, and difficulty of use-were rated lower than the scale's midpoint (see Figure 2). We describe these findings in more detail below.

5.4.1 Privacy. Participants rated privacy concerns highest of all our measured dimensions of user burden. Participants thought that the privacy policies of commercially available networked devices were somewhat untrustworthy $(M=2.0, S D=1.0)$. When participants were then asked to envision how a stickers system might enable networking of everyday domestic objects, they were somewhat worried about what information would be shared $(M=1.72, S D=1.2)$.

5.4.2 Financial Costs. Participants were somewhat concerned with the financial costs of a stickers system. They rated the stickers system as a little expensive $(M=1.28, S D=1.1)$, and their financial concerns increased slightly when asked about the upfront investment of $\$ 300$ for an IoT lightbulb $(M=1.68, S D=1.2)$.

5.4.3 Difficulty of Use. Participants rated a prospective IoT Sticker system's difficulty of use low with the exception of the ability to use it independently. Most participants $(n=19)$ stated that they needed to work with someone else to come up with an object idea very often or sometimes $(M=2.36$, $S D=1.0)$. However, once participants were able to come up with an idea, they expended little time $(M=0.5, S D=0.8)$ and mental effort to create an entry for that object $(M=1.0, S D=0.9)$. When asked whether the thought process was difficult to get into, participants largely disagreed $(M=1, S D=1.1)$, and the majority thought that it was only a little difficult or not at all difficult $(n=16)$. 
5.4.4 Differentiation. We asked participants to consider all of the objects they had described modifying in their home. They agreed that the system would require them to remember too much information to differentiate one modified object from another only a little bit $(M=0.84, S D=0.7)$.

5.4.5 Summary. Families raised more concerns about privacy in a prospective IoT Sticker system than all other measured dimensions. While families were somewhat sensitive to the prospective system's cost, the proposed price range was acceptable to most. Members thought that the prospective system was not very difficult to use in terms of the time required and mental effort needed, although they did frequently work with others to do so. On the whole, the user burden ratings did not identify significant burdens with the approach, but did reveal that privacy and independent use would be moderate concerns.

\section{LIGHTWEIGHT MODIFICATION FRAMEWORK}

Our findings reveal a framework for designers and builders to think about upcycling existing objects with cutting edge technology. We use the internet-of-things as a case study of how technology adoption could be reimagined to include the routines, habits, and arrangements that households use to sustain artifacts' roles within and as part of their relationships. Our framework does this by making the work households do to learn, adapt, and personalize objects within the home an explicit part of the upcycling process. The Framework for Lightweight Modification centers four axes of the household's process:

- Object Relationships

- Family Relationships

- Societal Relationships

- Time Use for Evolving Relationships

Unlike many conceptual frameworks, ours is not a stage-based model in which each facet can be cleanly separated from the others (see Figure 3). Instead, each stands in tension with the others. For example, generating ideas can be constrained by the shared home model as when feasibility and societal norms upheld by the family curtail ideas before they are ever seriously considered. While others have emphasized the importance of families individuating artifacts and weaving them into their household's routines $[8,14,53,70,76]$, our framework characterizes how upcycling with cutting edge technologies could be situated in the ways families currently make and construct a shared home by focusing attention on four central axes of domestic IoT: object relationships, family relationships, societal relationships, and time use.

\subsection{Object Relationships}

While our findings describe how families generate ideas for upcycling, object relationships are at the center of this process. Lightweight modification of possessions calls attention to those objects with malleable relationships. For example, objects in particular rooms can be held to higher ideals than their counterparts in other rooms; and so, are targeted for improvement. The intimacy of the bedroom meant that their owners had greater discretion over modifying those objects without having to compromise with others. Thus, these objects were targeted for meeting their owner's standards of comfort and ease. As they are owned by a single owner or intimate couple, they are subject to highly developed conceptions of what comfort and ease should be like. Transitional object relationships, like improvement, reveal ways that owner-object relationships change and create opportunities for lightweight modification to complement and nurture this change. 

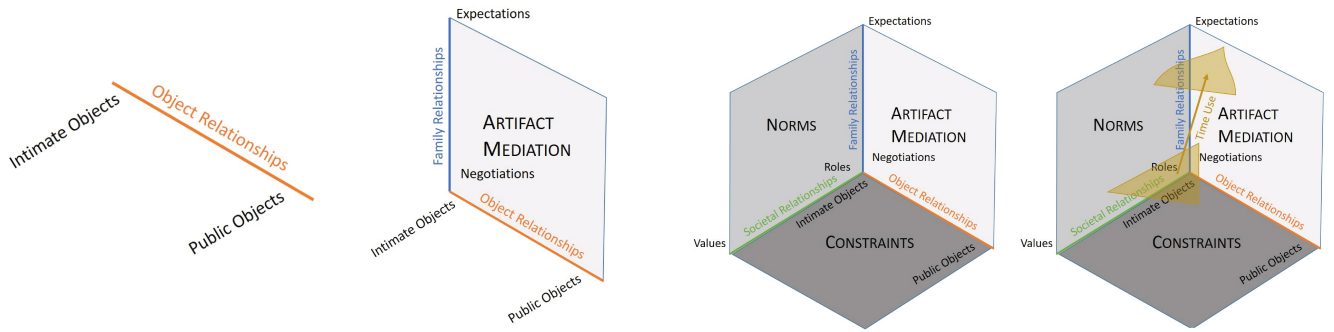

Fig. 3. The diagram shows the four axes of the Lightweight Modification Framework. As each axis is introduced, the range of concepts that axis captures are labeled and the attendant interactions are captured by the span of those axes with the exception of Time Use. The way the home's relationships evolve is conveyed as the change of the family's model of the home at two different stages.

\subsection{Family Relationships}

Our framework's second axis-family relationships-emphasizes the importance of families reaching an agreement on the household's norms and a shared idea of how the family should live when contesting and reconciling a model of home. A shared model assigns roles to household members around maintenance and care for the home and its objects. In contrast to intimate spaces like bedrooms and bathrooms, the shared nature of the livingroom and kitchen meant objects were subject to negotiation among residents. Hence, shared objects bore evolving relationships with other household members. Our findings showcase how family relationships are implicated in lightweight modification as when family members use collaborative processes like checking in with one another about ideas or testing whether the idea could be feasibly accommodated by others. These processes maintain family relationships and are important for family agreement and awareness that new norms will be shared.

\subsection{Societal Relationships}

Third in our framework is the set of relationships the home has with society. These relationships were present in values family members placed on the public face of the living room or kitchen. The living room needed to appear aesthetically pleasing to an external observer and meals prepared at home for children needed to be healthy. Societal relationships constrain which modification ideas will be considered by the family and how those ideas will unfold in any particular home by embodying community norms. These relationships also were revealed when discussing external models such as a restaurant, hotel, or other public spaces that could possibly assign new roles to family members. Public places offered family members new ways to stretch what was expected of their domestic role by suggesting alternative modes of care and maintenance for the home's objects and family relationships.

\subsection{Time Use for Evolving Relationships}

Our final framework axis-Time Use-brings attention to the demands an IoT system places on family members. Notably, family members already have established routines that they use to take time to reflect and plan for day to day activities. This suggests that while time is precious, families are willing to use it to try out new ways of accomplishing subtasks for their already complex routines; or, for less ingrained routines, creating any routine at all. This is especially true if there is perceived value around that time. Our findings revealed that some families enjoyed a chance to build off one another's creative ideas when working together, but that this could be thought of 
as a chore if family members struggle to come up with modification ideas. Further, we found that local leads are critical for ensuring the time is set aside and used constructively to integrate a new modification, however lightweight it may be. Time use characterizes the limited resources that families have to invest in evolving object, family, and societal relationships.

\subsection{Employing the Framework}

Any design approach that introduces new technology in the home through lightweight modification of everyday objects will need to confront the home's existing relationships and time use to address how those relationships will be reconfigured through modification. Previous work has explored the range of new possibilities modifying everyday objects like scissors, bottles, and coffee tumblers creates $[19,44,64]$, but the way these modifications will alter or change the relationships people have with those objects has not been looked at with the same critical lens that social IoT has brought to internet enabled devices [65]. Unlike investment and alteration rituals for previously owned artifacts or disposal practices [57], designing for lightweight modification will require helping owners use their current object relationships and attachments as a raw material.

To show how our framework calls attention to design requirements critical for modification of domestic possessions, we consider an example from prior research on IoT: the digital family portrait [52]. The digital family portrait is a picture frame instrumented with a digital display that updates with data sensed from a remote home. The portrait serves to communicate daily activity information of an elder with their family members living far away. The picture frame is a common household object seen in the living room. As such, the process of observing visual reminders of a loved one conforms to existing object relationships with picture frames. However, the frame alters the social relationships between elderly adults and their family members by disclosing activity information from sensors installed throughout their home. The portrait instantiates new ways of realizing societal values of the family's role in supporting elder members during later life stages by envisioning ways that elderly members can remain at home yet still have access to social support and care through their relatives. These are design features explicitly factored in by the digital family portrait's creators [52].

Additionally, our framework calls attention to trade-offs made during design decisions that need considered going forward. What is the Digital Family Portrait's Time Use? The researchers describe a several month process during which they retrofit the elder member's home with new sensor technologies and tailored the prototype to the field site [62]. While it is unclear whether this is an artifact of the system being a research prototype, prior work on sensor setup and home installation shows that installation is not a trivial task [14,50]. Leaving this aside, Time Use reveals aspects of how the object and family relationships evolved. The sensor system became invisible to the elderly member and concerns with surveillance by another family member faded as the implications of the system were experienced [52, 62]. Lastly, families developed alternative ways of providing support and caring for one another as they lived with the Digital Family Portrait. Collected data prompted family members to check in with phone calls and prompted new conversations such as inquiring about unusual levels of activity [52,62]. While monitoring the impact of a new technology on the home is a standard component of user studies, our framework suggests that these findings need compared to an understanding of the same home's coordination patterns prior to intervention to assess the full path of how the Digital Family Portrait evolved relationships.

\subsection{Summary}

In summary, our framework delimits the principle axes for evolving malleable relationships with domestic IoT. These four axes can inform designers and builders of principle dimensions to address 
when considering how domestic IoT might be adopted: object, family, and societal relationships, and time use for evolving these relationships.

\section{DISCUSSION}

We worked with 10 families to develop our framework of the dimensions of home life involved when families tailor an IoT system to their domestic environment. When families do so, they suspend belief in the current home to consider how objects and rooms might be reconfigured. Object proposals help family members destabilize the working model of home to include previously unthought of arrangements. However, this process of tailoring IoT to the home makes demands of family members' time. This pushes families to adopt differing community dynamics where a local lead fosters that family coordination and collaboration. However, as the level of analysis shifts to include all four of our framework's axes, we find that household members begin to disagree about how object, social, and societal relationships should evolve and be realized in the future, desired home. Time Use, then, constitutes the processes through which families negotiate and compromise on their planned changes.

\subsection{Debugging Reconfigured Objects and Roles}

To support families in coming to accept a proposal, a tailorable IoT will need to enable collective debugging. Family norms emphasize a need for supporting members with imagining alternative arrangements, and so there is an opportunity for tailorable IoT systems to support experimentation with new roles and trying new configurations. Yet, these systems make demands on family time to ensure all members' views are represented in a proposed modification. To address these needs, the barrier to entry to become a local lead needs to be perceived as low and valuable. Prior work has shown that leadership for smart home installation can be seen as a hobbiest enterprise that is intrinsically enjoyed by one member of the household [14, 22, 50, 76]. However, our findings show that this kind of leadership could be present in only a small fraction of households. Instead, when considered from the perspective of our framework, we show how local leadership often happens in coordination with other household members (a finding visible in the results of prior work [14, 50]). There is a shared decision to adopt the ideas of one member or agreement to follow another's lead.

This suggests that lowering barriers to IoT systems should also include making coordination with other members easier through sharing example ideas, eliciting feedback, and prompting others with questions. These kinds of systems that enable groups to work as teams and elect one person as project manager are a longstanding contribution of the CSCW research in the workplace. However, our framework identifies an opportunity for translating this system design to at-home collaboration. We do not suggest that the same workplace values of efficiency and productivity are appropriate, but our framework does reveal that some domestic contexts are appropriate for using collaborative management tools in order to support social debugging. For example, modification designs that supported voting mechanisms would enable other family members to contribute an opinion about whether the modified object would be successful. Copy/paste mechanisms would allow one person to borrow the idea of another person but extend it as well. Lastly, an annotation mechanism with a prompting question could bring one household member's attention to an incomplete modification initially created by another. Although prior work [14] points out the importance of debugging new DIY-IoT rules during the course of everyday routines, we argue that an important part of debugging will be how relationships are newly configured. Unlike the debugging process discussed in the end user development literature [14,31], families will need ways to debug newly constructed relationships. To meet this challenge, focusing on an originator's debugging process is insufficient. Instead, systems will need to support social debugging so that an object's modification can be tolerated by others and acceptable to all. 


\subsection{Modularity in the Home}

Our findings revealed that families use rooms to categorize their objects and activities. Object types are not treated equivalently across rooms (e.g. a TV in the living room verses the bedroom). These results show that family members exercise room-level control by regulating what goes in and out of that room (such as P5b disabling internet access in her children's bedroom). These findings suggest that an IoT supportive of local area networks at the range of the room could enable new kinds of interaction techniques and help families manage costs. For example, room-level networks and room-specific parameters for objects could support fine-grained expectations for different parts of the home (an issue identified in early smart home research [25]). Our framework shows how intimate spaces like bedrooms and bathrooms are more supportive of object relationships while semi-public spaces like livingrooms and kitchens are subject to greater negotiation and concerns with how the family is viewed by the greater community. Further, families could make piecemeal investments in IoT-one room or one object at a time-to better manage and shape the impact newly modified objects have on the family (resonating with a smarthome adoption pattern reported in earlier research [25]). These abilities are well within the reach of current IoT research (e.g., IoT light bulb [34]).

\subsection{Upcycling}

Our work is motivated by the claim that the costs of IoT adoption need to be considered in design. We argue that a tailorable IoT that can be adapted to domestic possessions could address the hidden costs of replacement such as minimizing waste, evolving family members' attachment to their possessions, and reconfiguring entrenched routines. We recommend ways for mitigating these costs such as fostering communities supportive of social debugging and supporting granular control over IoT's introduction to the home in system design. Yet our work engages upcycling questions shared by the research community on whether upcycled objects can, indeed, offer greater value than before modification [69]. Our findings and framework help lay the groundwork for thinking about these questions by revealing opportunities and needs within current household dynamics around upgrading the home to address experimentation with household roles and historical, social legacies (e.g., gender or age) [25,69]. While prior work suggests that differentiating subgroups of the populations reveal differing values around upcycling [69], we identify opportunities to destabilize traditional groupings-such as gender or age-during the upcycling process by experimenting with the home's malleable relationships.

Prior work called attention to questions around "how to imbue an object with potential for imaginitive reuse by individuals" [12]. We find that families already employ coordination patterns that could enable collaborative creativity by building off one another's ideas and experimenting with alternative roles. There is an opportunity for the embeddedness of IoT to scaffold object-oriented creativity through helping reshape object relationships by suggesting experiments for new object roles or role play with the alternative social arrangements afforded through those objects. While our framework does not provide a definitive answer for how individuals might upcycle objects, it delimits four principle axes-object relationships, social relationships, societal relationships, and time use-along which households could be supported.

\subsection{Limitations}

While we made every effort to target and recruit households from lower socio-economic statuses than previously focused on in smarthome research, we were unable to fully represent those views here. For one reason, we excluded the household's data with the lowest SES because they did not complete the audio diary task. We struggle to explain this as they were able to complete the home 
tour and facilitated audio diary task without any problems. Future work should examine whether our framework emphasizes the appropriate dimensions of DIY-IoT for lower SES families.

Our study worked with only 10 households in one American city. We specifically tried to target a representative sample for the location where our study was conducted. Working in depth with each family over 7 days allowed us to capture nuances in how families collaborate when modifying domestic objects that could not be captured in a shorter or more targeted study. Yet, one city and 10 households is not enough to fully characterize how lightweight modification will occur in all households. Specifically, other cultures should be examined. While prior work has examined how DIY-IoT may occur in Europe and East Asia, this leaves a majority of the world untouched. Different cultures will undoubtedly result in alternative family dynamics, and it remains an open question whether our framework would still characterize these alternatives. A larger number of households should also be examined to ensure validity of our framework for other cities and also at scale. To scale our study, researchers should focus on assessing whether principle axes still resolve around object relationships, social relationships, societal relationships, and time use.

\section{CONCLUSION}

From our work with 10 American families over 7 days, we developed a framework for tailoring IoT to the household's existing possessions. This framework creates a path for upcycling domestic possessions with new IoT services. We show how family dynamics could nurture each household member to contribute to an IoT supportive of the family's model of home. We also outline IoT design opportunities for social debugging and piecemeal investment at the level of the home's objects and rooms. Future work should examine access to DIY-IoT for low SES housheolds and verify our framework's applicability to other cultures and communities. In the work we present here, we show how lightweight modifications of the home's everyday objects creates an alternative pattern for IoT adoption that could be made sensitive to the costs of bringing new technology into the home.

\section{ACKNOWLEDGEMENTS}

We thank the Carnegie Library of Homewood, Vintage Senior Services, the Latino Community Center, the Persad Center, the Mentoring Partnership, Repair the World, and the Children's Museum of Pittsburgh for help with advertising and recruiting participants. This work was funded in part by National Science Foundation grant IIS-1718651.

\section{REFERENCES}

[1] 2001. Home Possessions: Material Culture behind Closed Doors. Berg Publishers, Oxford, UK.

[2] 2013. Fast-Forward Family: Home, Work and Relationships in Middle-Class America. University of California Press, United States.

[3] 2019. Charmin Toilet Paper Dash Button. (2019). Retrieved January 16th, 2019 from https://www.amazon.com/ Amazon-JK29LP-Charmin-Dash-Button/dp/B01C3JAQDQ

[4] 2019. Google Home - Smart Speaker \& Home Assistant. (2019). Retrieved January 16th, 2019 from https://store.google. com/product/google_home

[5] 2019. IFFFT Helps Your Apps and Devices Work Together. (2019). Retrieved January 16th, 2018 from https://ifttt.com/

[6] 2019. Kadrilj Rollo. (2019). Retrieved January 16th, 2019 from https://www.ikea.com/de/de/catalog/products/20408116/ ?query=Kadrilj

[7] 2019. Smart Home Lighting. (2019). Retrieved January 16th, 2019 from https://www2.meethue.com/en-us

[8] Aloha Ambe, Margot Brereton, Alessandro Soro, and Paul Roe. 2017. Technology Individuation: the Foibles of Augmented Everyday Objects. In Proceedings of the 2017 CHI Conference on Human Factors in Computing Systems. ACM, New York, New York, 6632-6644.

[9] Jeanne Arnold, Anthony Graesch, Enzo Ragazzini, and Elinor Ochs. 2012. Life at Home in the Twenty-first Century. Cotsen Institute Press, Los Angeles, CA. 
[10] Nivedita Arora, Steven L Zhang, Fereshteh Shahmiri, Diego Osorio, Yi-Cheng Wang, Mohit Gupta, Zhengjun Wang, Thad Starner, Zhong Lin Wang, and Gregory D Abowd. 2018. SATURN: A thin and flexible self-powered microphone leveraging triboelectric nanogenerator. Proceedings of the ACM on Interactive, Mobile, Wearable and Ubiquitous Technologies 2, 2 (2018), 60.

[11] Eli Blevis. Sustainable Interaction Design: Invention \& Disposal, Renewal \& Reuse. In Proceedings of the SIGCHI Conference on Human Factors in Computing. ACM, New York, NY, 503-512.

[12] Ben Bridgens, Mark Powell, Graham Farmer, Claire Walsh, Eleanor Reed, Mohammad Royapoor, Peter Gosling, Jean Hall, and Oliver Heidrich. 2018. Creative upcycling: Reconnecting people, materials and place through making. Journal of Cleaner Production 189 (2018), 145-154.

[13] A. J. Brush, Bongshin Lee, Ratul Mahajan, Sharad Agarwal, Stefan Saroiu, and Colin Dixon. Home Automation in the Wild: Challenges and Opportunities. ACM, New York, NY, 2115-2124.

[14] Jong bum Woo. 2015. User Experiences in Do-It-Yourself-Style Smart Homes. In Proceedings of the 2015 ACM International foint Conference on Pervasive and Ubiquitous Computing. ACM, New York, NY, 779-790.

[15] US Census Bureau. 2016a. 2012-2016 American Community Survey 5-year Estimates. (2016). Retrieved September 20th, 2018 from https://factfinder.census.gov/faces/nav/jsf/pages/index.xhtml

[16] US Census Bureau. 2016b. Characteristics of Same-Sex Couple Households. (2016). Retrieved September 20 th, 2018 from https://www.census.gov/data/tables/time-series/demo/same-sex-couples/ssc-house-characteristics.html

[17] US Census Bureau. 2017. US Census Bureau Quick Facts. (1 July 2017). Retrieved June 1st, 2018 from https: //www.census.gov/quickfacts/fact/table/US/PST045217

[18] Nico Castelli, Corinna Ogonowski, Timo Jakobi, Martin Stein, Gunnar Stevens, and Volker Wulf. 2017. What happened in my home?: An end-user development approach for smart home data visualization. In Proceedings of the $2017 \mathrm{CHI}$ Conference on Human Factors in Computing Systems. ACM, 853-866.

[19] Xiang'Anthony' Chen, Stelian Coros, Jennifer Mankoff, and Scott E Hudson. 2015. Encore: 3D printed augmentation of everyday objects with printed-over, affixed and interlocked attachments. In Proceedings of the 28th Annual ACM Symposium on User Interface Software \& Technology. ACM, 73-82.

[20] Marshini Chetty, Richard Banks, Richard Harper, Tim Regan, Abigail Sellen, Christos Gkantsidis, Thomas Karagiannis, and Peter Key. 2010. Who's hogging the bandwidth: the consequences of revealing the invisible in the home. In Proceedings of the SIGCHI Conference on Human Factors in Computing Systems. ACM, 659-668.

[21] Marshini Chetty, AJ Brush, Brian R Meyers, and Paul Johns. 2009. It's not easy being green: understanding home computer power management. In Proceedings of the SIGCHI Conference on Human Factors in Computing Systems. ACM, 1033-1042.

[22] Marshini Chetty, Ja-Young Sung, and Rebecca Grinter. 2007. How Smart Homes Learn: The Evolution of the Networked Home and Household. In Proceedings of the International Conference on Ubiquitous Computing. Springer, Berlin, Germany, 127-144.

[23] Tawanna Dillahunt, Jennifer Mankoff, Eric Paulos, and Susan Fussell. 2009. It's not all about Green: energy use in low-income communities. In Proceedings of the 11th International Conference on Ubiquitous Computing. New York, NY, 255-264.

[24] Lynn Dombrowski, Ellie Harmon, and Sarah Fox. 2016. Social justice-oriented interaction design: Outlining key design strategies and commitments. In Proceedings of the 2016 ACM Conference on Designing Interactive Systems. ACM, 656-671.

[25] Keith Edwards and Rebecca Grinter. 2001. At Home with Ubiquitous Computing: 7 Challenges. In Proceedings of the International Conference on Ubiquitous Computing. Springer, Berlin,Germany, 256-272.

[26] Michael Eisenberg, Ann Eisenberg, Leah Buechley, and Nwanua Elumeze. Invisibility Considered Harmful: Revisiting Traditional Principles of Ubiquitous Computing in the Context of Education. In Fourth IEEE International Workshop on Wireless, Mobile and Ubiquitous Technology in Education. IEEE Computing Society, Washington, DC, 103-110.

[27] Jodi Forlizzi. 2007. How Robotic Products Become Social Products: An Ethnographic Study of Cleaning in the Home. In Proceedings of the 3rd ACM/IEEE international conference on Human robot interaction. ACM, New York, NY, 129-136.

[28] Jon Froehlich, Leah Findlater, and James Landay. 2010. The design of eco-feedback technology. In Proceedings of the SIGCHI conference on human factors in computing systems. ACM, 1999-2008.

[29] Michelle Gantt and Bonnie A Nardi. 1992. Gardeners and gurus: patterns of cooperation among CAD users. In Proceedings of the SIGCHI conference on Human factors in computing systems. ACM, 107-117.

[30] Chuhan Gao, Yilong Li, and Xinyu Zhang. 2018. LiveTag: Sensing Human-Object Interaction Through Passive Chipless WiFi Tags. In USENIX Symposium on Networked Systems Design and Implementation. USENIX Association, Renton, WA, 533-546.

[31] Giuseppe Ghiani, Marco Manca, Fabio Paternò, and Carmen Santoro. 2017. Personalization of context-dependent applications through trigger-action rules. ACM Transactions on Computer-Human Interaction (TOCHI) 24, 2 (2017), 14.

[32] James Gibson. 1979. The Ecological Approach to Visual Perception. Houghton Mifflin, Boston, MA. 
[33] Dennis Gilber. 1998. The American Class Structure. Wadsworth Publishing Company, Belmont, CA.

[34] Jeremy Gummeson, James McCann, Chouchang (Jack) Yang, Damith Ranasinghe, Scott Hudson, and Alanson Sample. 2017. RFID Light Bulb: Enabling Ubiquitous Deployment of Interactive RFID Systems. In Proceedings of the ACM on Interactive, Mobile, Wearable and Ubiquitous Technologies, Vol. 1. ACM, New York, New York. Issue 2.

[35] Eva Hornecker and Jacob Buur. 2006. Getting a Grip on Tangible Interaction: a Framework on Physical Space and Social Interaction. In Proceedings of the SIGCHI Conference on Human Factors in Computing Systems. ACM, New York, New York, 437-446.

[36] Jan Humble, Andy Crabtree, Terry Hemmings, Karl-Petter Åkesson, Boriana Koleva, Tom Rodden, and Pär Hansson. 2003. Playing with the Bits: User-configuration of Ubiquitous Domestic Environments. In International Conference on Ubiquitous Computing. Springer, 256-263.

[37] Giulio Iacucci, Kari Kuutti, and Mervi Ranta. 2000. On the move with a magic thing: role playing in concept design of mobile services and devices. In Proceedings of the 3rd conference on Designing interactive systems: processes, practices, methods, and techniques. ACM, 193-202.

[38] Sarah Inman and David Ribes. 2019. "Beautiful Seams": Strategic Revelations and Concealments. In Proceedings of the 2019 CHI Conference on Human Factors in Computing Systems. ACM, 278.

[39] Hiroshi Ishii and Brygg Ulmer. 1997. Tangible Bits: Towards Seamless Interfaces between People, Bits, and Atoms. In Proceedings of the SIGCHI Conference on Human Factors in Computing Systems. ACM, New York, New York, $234-241$.

[40] Rikke Hagensby Jensen, Yolande Strengers, Jesper Kjeldskov, Larissa Nicholls, and Mikael B Skov. 2018. Designing the desirable smart home: A study of household experiences and energy consumption impacts. In Proceedings of the 2018 CHI Conference on Human Factors in Computing Systems. ACM, 4.

[41] Heekyoung Jung, Erik Stolterman, Will Ryan, Tonya Thompson, and Marty Siegel. 2008. Toward a Framework for Ecologies of Artifacts: How are Digital Artifacts Interconnected Within a Personal Life?. In Proceeding of the SIGCHI Conference on Human Factors in Computing Systems. ACM, New York, NY, 201-210.

[42] Yoshihiro Kawahara, Steve Hodges, Benjamin Cook, Chang Zhang, and Gregory Abowd. 2013. Instant Inkjet Circuits: Lab-based Inkjet Printing to Support Rapid Prototyping of UbiComp Devices. In Proceedings of the 2013 ACM International foint Conference on Pervasive and Ubiquitous Computing. ACM, New York, New York, 363-372.

[43] Sunyoung Kim and Eric Paulos. 2011. Practices in the Creative Reuse of E-Waste. In Proceeding of the SIGCHI Conference on Human Factors in Computing Systems. ACM, New York, NY, 2395-2404.

[44] Robert Kovacs, Anna Seufert, Ludwig Wall, Hsiang-Ting Chen, Florian Meinel, Willi Müller, Sijing You, Maximilian Brehm, Jonathan Striebel, Yannis Kommana, and others. 2017. TrussFab: fabricating sturdy large-scale structures on desktop 3D printers. In Proceedings of the 2017 CHI Conference on Human Factors in Computing Systems. ACM, 2606-2616.

[45] Christopher Lalau-Keraly, George Daniel, Joseph Lee, and David Schwartz. 2017. Peel-and-Stick Sensors Powered by Directed RF Energy. In ASME 2017 International Technical Conference and Exhibition on Packaging and Integration of Electronic and Photonic Microsystems collocated with the ASME 2017 Conference on Information Storage and Processing Systems. American Society of Mechanical Engineers, V001T03A005-V001T03A005.

[46] Jonathan Lazar, Jinjuan Heidi Feng, and Harry Hochheiser. 2017. Research methods in human-computer interaction. Morgan Kaufmann

[47] Hanchuan Li, Eric Brockmeyer, Elizabeth Carter, Josh Fromm, Scott Hudson, Shwetak Patel, and Alanson Sample. 2016. PaperID: A Technique for Drawing Functional Battery-Free Wireless Interfaces on Paper. In Proceeding of the SIGCHI Conference on Human Factors in Computing Systems. ACM, New York, NY, 5885-5896.

[48] Allan MacLean, Kathleen Carter, Lennart Lovstrand, and Thomas Moran. 1990. User-Tailorable Systems: Pressing the Issues with Buttons. In Proceedings of the SIGCHI Conference on Human Factors in Computing. ACM, New York, NY, 175-182.

[49] Douglass Massey and Nancy Denton. 1993. American Apartheid: Segregation and the Making of the Underclass. Harvard University Press, Cambridge, MA.

[50] Sarah Mennicken and Elaine M. Huang. 2012. Hacking the Natural Habitat: an In-the-wild Study of Smart Homes, Their Development, and the People Who Live in Them. In Proceedings of the 10th international conference on Pervasive Computing. Springer, Berlin, Germany, 143-160.

[51] Peter Menzel. 1994. Material World: a Global Family Portrait. Sierra Club Books, San Francisco, CA.

[52] Elizabeth D Mynatt, Jim Rowan, Sarah Craighill, and Annie Jacobs. 2001. Digital family portraits: supporting peace of mind for extended family members. In Proceedings of the SIGCHI conference on Human factors in computing systems. ACM, 333-340.

[53] Bjorn Nansen, Luke van Ryn, Frank Vetere, Toni Robertson, Margot Brereton, and Paul Dourish. 2014. An internet of social things. In Proceedings of the 26th Australian Computer-Human Interaction Conference on Designing Futures: the Future of Design. ACM, 87-96. 
[54] Will Odom, James Pierce, Erik Stolterman, and Eli Blevis. 2009. Understanding Why We Preserve Some Things and Discard Others in the Context of Interaction Design. In Proceeding of the SIGCHI Conference on Human Factors in Computing Systems. ACM, New York, NY, 1053-1062.

[55] Women's Bureau of Labor and Statistics. 2014. Mothers and Families. (August 2014). Retrieved September 20 th, 2018 from https://www.dol.gov/wb/stats/mother_families.htm

[56] Katie O’Leary, Tao Dong, Julia Katherine Haines, Michael Gilbert, Elizabeth Churchill, and Jeffrey Nichols. 2017. The Moving Context Kit: Designing for Context Shifts in Multi-Device Experiences. In Proceedings of the 2017 Conference on Designing Interactive Systems. ACM, New York, NY, 309-320.

[57] James Pierce and Eric Paulos. 2011. Second-Hand Interactions: Investigating Reacquisition and Dispossession Practices around Domestic Objects. In Proceeding of the SIGCHI Conference on Human Factors in Computing Systems. ACM, New York, NY, 2385-2394.

[58] Chris Preist, Dan Schien, and Eli Blevis. 2016. Understanding and Mitigating the Effects of Device and Cloud Service Design Decisions on the Environmental Footprint of Digital Infrastructure. In Proceedings of the SIGCHI Conference on Human Factors in Computing Systems. ACM, New York, NY, 1324-1337.

[59] William Rathje and Cullen Murphy. 1992. Rubbish! The Archaeology of Garbage. Harper Collins, New York, NY.

[60] Jennifer Rode, Eleanor Toye, and Alan Blackwell. 2004. The Fuzzy Felt Ethnography-Understanding the Programming Patterns of Domestic Appliances. Personal and Ubiquitous Computing (2004), 161-176.

[61] Yvonne Rogers. 2006. Moving on from Weiser's Vision of Calm Computing: Engaging UbiComp Experiences. In International Conference on Ubiquitous Computing. Springer, Berlin, Germany, 404-421.

[62] Jim Rowan and Elizabeth D Mynatt. 2005. Digital family portrait field trial: Support for aging in place. In Proceedings of the SIGCHI conference on Human factors in computing systems. ACM, 521-530.

[63] Ari Schlesinger, W Keith Edwards, and Rebecca E Grinter. 2017. Intersectional HCI: Engaging identity through gender, race, and class. In Proceedings of the 2017 CHI Conference on Human Factors in Computing Systems. ACM, 5412-5427.

[64] Rita Shewbridge, Amy Hurst, and Shaun K Kane. 2014. Everyday making: identifying future uses for 3D printing in the home. In Proceedings of the 2014 conference on Designing interactive systems. ACM, 815-824.

[65] Alessandro Soro, Margot Brereton, and Paul Roe. 2018. Social Internet of Things. Springer.

[66] Andrew Speilberg, Alanson Sample, Scott Hudson, Jennifer Mankoff, and James McCann. 2016. RapID: A Framework for Fabricating Low-Latency Interactive Objects with RFID Tags. In Proceeding of the SIGCHI Conference on Human Factors in Computing Systems. ACM, New York, NY, 5897-5908.

[67] Heywon Suh, Nina Shahriaree, Eric Heckler, and Julie Kientz. 2016. Developing and Validating the User Burden Scale: a Tool for Assessing User Burden in Computing Systems. In Proceedings of the SIGCHI Conference on Human Factors in Computing. ACM, New York, NY, 3988-3999.

[68] Kyungeun Sung. 2015. A Review on Upcycling: Current Body of Literature, Knowledge Gaps and a Way Forward. In The ICECESS 2015: 17th International Conference on Environmental, Cultural, Economic and Social Sustainability. World Academy of Science, Engineering and Technology (WASET), Venice, Italy, 28-40.

[69] Kyungeun Sung, Tim Cooper, and Sarah Kettley. 2015. An exploratory study on the links between individual upcycling, product attachment, and product longevity. Nottingham Trent University.

[70] Alex Taylor, Richard Harper, Laurel Swann, Shaharam Izadi, Abigail Sellen, and Mark Perry. 2007. Homes that Make Us Smart. Personal and Ubiquitous Computing (2007), 383-393.

[71] Khai N Truong, Elaine M Huang, and Gregory D Abowd. 2004. CAMP: A magnetic poetry interface for end-user programming of capture applications for the home. In International Conference on Ubiquitous Computing. Springer, 143-160.

[72] Blase Ur, Melwyn Pak Yong Ho, Stephen Brawner, Jiyun Lee, Sarah Mennicken, Noah Picard, Diane Schulze, and Michael L Littman. 2016. Trigger-action programming in the wild: An analysis of 200,000 IFTTT recipes. In Proceedings of the 2016 CHI Conference on Human Factors in Computing Systems. ACM, 3227-3231.

[73] Dhaval Vyas. 2012. Domestic Artefacts: Sustainability in the Context of Indian Middle Class. In Proceedings of the 4th International Conference on Intercultural Collaboration. ACM, New York, NY, 119-128.

[74] Mark Weiser. 1991. The computer of the 21st century. Mobile Computing and Communications Review 3, 3 (1991).

[75] Dae Seung Wie, Yue Zhang, Min Ku Kim, Bongjoong Kim, Sangwook Park, Young-Joon Kim, Pedro P. Irazoqui, Xiaolin Zheng, Baoxing Xu, and Chi Hwan Lee. 2018. Wafer-recyclable, Environment-friendly Transfer Printing for Large-scale Thin-Film Nanoelectronics. In Proceedings of the National Academy of Science, Vol. 115. PNAS.

[76] Charlie Wilson and Tom Hargreaves. 2015. Smart Homes and Their Users: a Systematic Analysis and Key Challenges. Personal and Ubiquitous Computing 19, 2 (2015).

Received April 2019; revised June 2019; accepted August 2019

Proc. ACM Hum.-Comput. Interact., Vol. 3, No. CSCW, Article 185. Publication date: November 2019. 